\title{
Editorial: Challenges of Hydrological Drought Monitoring and Prediction
}

\author{
Juan A. Rivera ${ }^{1 *}$, Johnna Maria Infanti ${ }^{2}$, Rohini Kumar ${ }^{3}$ and Joseph Nzau Mutemi ${ }^{4}$ \\ ${ }^{1}$ Instituto Argentino de Nivología, Glaciología y Ciencias Ambientales (IANIGLA), Centro Científico-Tecnológico CONICET \\ Mendoza, Mendoza, Argentina, ${ }^{2}$ NOAA/NWS/NCEP/Climate Prediction Center/Innovim, College Park, MD, United States, \\ ${ }^{3}$ Helmholtz Centre for Environmental Research (UFZ), Leipzig, Germany, ${ }^{4}$ Department of Meteorology, University of Nairobi, \\ Nairobi, Kenya
}

Keywords: hydrological drought, hydrological cycle, remote sensing, water resources, drought monitoring

Editorial on the Research Topic

\section{Challenges of Hydrological Drought Monitoring and Prediction}

Hydrological droughts are complex recurring hazards that can cause water shortages in streams or storages such as reservoirs, lakes, groundwater, and snowpacks, resulting in negative impacts to natural and socio-economic systems (Mishra and Singh, 2010; Van Loon, 2015). While significant advances in hydrological drought research were documented in the recent years (Hasan et al., 2019), challenges remain in terms of quantifying the drought signal in all the components of the hydrological cycle (Van Loon, 2015, Stahl et al., 2020), modeling and predicting droughts (Sutanto et al., 2020; Brunner et al., 2021), and in the operational aspects of hydrological drought monitoring (Cammalleri et al., 2020). The manuscripts included in this Research Topic aim to provide new perspectives on hydrological drought monitoring and prediction, highlighting existing challenges and opportunities for the generation of usable information to assist decision water management policy decision making.

Using observations of precipitation, groundwater levels, and surface water, together with remotely sensed data of soil moisture and vegetation greenness, Buitink et al. showed the existence of a drought frequency paradox: when viewed across a complex hydrological system, droughts are common rather than rare. This is due to the different responses across the hydrological system, and to the spatial variability present within each component of the hydrological system. The authors highlighted that improved drought monitoring can be achieved if all relevant variables are considered in a compound drought index specific to the area of interest. However, how to combine and aggregate different drought indices for better decision-making in water resources management is still a subject of debate (Yihdego et al., 2019). Following a drought propagation approach, Yeh used long-term records of precipitation and groundwater from three river basins in Central Taiwan to investigate the changes in drought parameters as frequency, duration and severity, between meteorological and groundwater droughts. The pooling of drought events, one of the commonly observed characteristics of drought propagation (Van Loon and Van Lanen, 2012), was observed particularly during severe drought events, when meteorological droughts occurred at a higher frequency than those identified through groundwater levels.

Gutierrez-Cori et al. explored the relationship between vegetation changes in the southern Amazon basin and hydroclimatic factors. The predominant land cover types exhibited different responses to the hydroclimate variability, particularly during extreme drought years. Moreover, the marked rainfall seasonality generates a dependency of vegetation to water availability during the months outside the peak of the wet season. In comparison to runoff or rainfall, the total water storage resulted in a better indicator of the variability of evergreen forests, a factor that highlights the use of remote sensing products to characterize the vegetation-hydrology dynamics, which are also affected by the land cover changes due to deforestation over the last 20 years. A better 
characterization of the land-atmosphere interactions that modulate the regional hydrological cycle could be achieved through the use of land surface models. In this sense, there have been many efforts to produce accurate precipitation estimates for use in land surface process studies (Shrestha et al., 2020), particularly in areas of complex terrain due to limitations of observing systems and large spatial variability (Hughes et al., 2020). Sarmiento et al. compared the Integrated Multi-satellite Retrievals for GPM (IMERG) and the Climate Hazards Group InfraRed Precipitation with Stations version 2 (CHIRPS2) rainfall products over the continental United States to quantify the impacts of the daily distribution of precipitation on biases and errors in simulated hydrological variables. A combination of IMERG and CHIRPS2 resulted in a reduction of the number of dry days and an increase in the frequency of low rainfall days, which led to a better simulation of surface soil moisture, surface runoff, and evapotranspiration. This is particularly relevant for a better characterization of hydrological droughts through the use of land surface models, with the potential to provide relevant information for water managers (Quintana-Seguí et al., 2020; Peters-Lidard et al., 2021).

Two recent case studies focusing on the evaluation of extreme hydrological drought events in South America were also part of this Research Topic. In the first study, Marengo et al. analyzed the extreme drought that is affecting since 2019 the Pantanal region, one of the largest wetlands of the world and an important biodiversity hotspot. The authors used a variety of observations and remote sensing products to quantify the hydrological drought conditions and its impacts on human activities and natural systems. The reduced hydrometric levels throughout the Paraguay river affected the navigability of the waterway, impacting in the exports of crops and minerals from Bolivia, Brazil and Paraguay. The decrease in precipitation, caused by reduced transport of warm and humid air from Amazonia, generated also a water mass decrease over the floodplain, affecting the vegetation health over the region. In a second study, Rivera et al. focused on the evaluation of the record-breaking hydrological drought over

\section{REFERENCES}

Brunner, M. I., Slater, L., Tallaksen, L. M., and Clark, M. (2021). Challenges in modeling and predicting floods and droughts: a review. WIREs Water 8:e1520. doi: $10.1002 /$ wat 2.1520

Cammalleri, C., Barbosa, P., and Vogt, J. V. (2020). Evaluating simulated daily discharge for operational hydrological drought monitoring in the Global Drought Observatory (GDO). Hydrol. Sci. J. 65, 1316-1325. doi: 10.1080/02626667.2020.1747623

Hasan, H. H., Mohd Razali, S. F., Muhammad, N. S., and Ahmad, A. (2019). Research trends of hydrological drought: a systematic review. Water 11:2252. doi: 10.3390/w11112252

Hughes, M., Lundquist, J. D., and Henn, B. (2020). Dynamical downscaling improves upon gridded precipitation products in the Sierra Nevada, California. Clim. Dyn. 55, 111-129. doi: 10.1007/s00382-017-3 631-z

Mishra, A. K., and Singh, V. P. (2010). A review of drought concepts. J. Hydrol. 391, 202-216. doi: 10.1016/j.jhydrol.2010.07.012 central-western Argentina, an arid to semi-arid region where snowmelt in the Andes ranges is key to sustain the irrigation of the agricultural oases and the drinking water supply. Using streamflow observations from the main basins of the region, the authors applied the variable threshold-level method and the standardized streamflow index, which are used increasingly for real-time monitoring of hydrological drought conditions (Stahl et al., 2020), to quantify the spatio-temporal characteristics of the drought event. Recommendations were provided for an improved drought monitoring over the region, considering the paucity of snow and groundwater records, the low density rainfall and runoff observations, and the current limitations of the snowmelt forecasts.

Overall, two main aspects can be highlighted in these six studies covered within the Research Topic: (1) the role of remote sensing to quantify the available regional water resources and the propagation of the drought signal into the hydrological cycle; and (2) the recommendations for improved hydrological drought monitoring and prediction, which can be used either in the drafting or in the revision of existing drought contingency plans. These aspects are of critical importance for setting up strategies for reducing the vulnerability to drought and improving drought response at regional and local level.

\section{AUTHOR CONTRIBUTIONS}

JR wrote the draft of the manuscript. JI, RK, and JM edited and commented on the draft. All authors approved the manuscript for publication.

\section{ACKNOWLEDGMENTS}

We want to thank all the authors that contributed to this Research Topic, as well as the reviewers that ensured the high quality of the manuscripts. JR wants to thank the National Agency for Scientific and Technological Promotion (ANPCyT) of Argentina for supporting the research in the field of hydrological droughts [grant number PICT-2016-0431].

Peters-Lidard, C. D., Mocko, D. M., Su, L., Lettenmaier, D. P., Gentine, P., and Barlage, M. (2021). Advances in land surface models and indicators for drought monitoring and prediction. Bull. Am. Meteorol. Soc. 102, E1099E1122. doi: 10.1175/BAMS-D-20-0087.1

Quintana-Seguí, P., Barella-Ortiz, A., Regueiro-Sanfiz, S., and MiguezMacho, G. (2020). The utility of land-surface model simulations to provide drought information in a water management context using global and local forcing datasets. Water Resour. Manage. 34, 2135-2156. doi: 10.1007/s11269-018-2160-9

Shrestha, A., Nair, A. S., and Indu, J. (2020). Role of precipitation forcing on the uncertainty of land surface model simulated soil moisture estimates. J. Hydrol. 580:124264. doi: 10.1016/j.jhydrol.2019.124264

Stahl, K., Vidal, J.-P., Hannaford, J., Tijdeman, E., Laaha, G., Gauster, T., et al. (2020). The challenges of hydrological drought definition, quantification and communication: an interdisciplinary perspective. Proc. IAHS 383, 291-295. doi: 10.5194/piahs-383-291-2020

Sutanto, S. J., Wetterhall, F., and Van Lanen, H. A. J. (2020). Hydrological drought forecasts outperform meteorological drought 
forecasts. Environ. Res. Lett. 15:084010. doi: 10.1088/1748-9326/a b8b13

Van Loon, A. F. (2015). Hydrological drought explained. WIREs Water 2, 359-392. doi: $10.1002 /$ wat2.1085

Van Loon, A. F., and Van Lanen, H. A. J. (2012). A process-based typology of hydrological drought. Hydrol. Earth Syst. Sci. 16, 1915-1946. doi: 10.5194/hess-16-1915-2012

Yihdego, Y., Vaheddoost, B., and Al-Weshah, R. A. (2019). Drought indices and indicators revisited. Arab. J. Geosci. 12:69. doi: 10.1007/s12517-019-4237-z

Conflict of Interest: The authors declare that the research was conducted in the absence of any commercial or financial relationships that could be construed as a potential conflict of interest.
Publisher's Note: All claims expressed in this article are solely those of the authors and do not necessarily represent those of their affiliated organizations, or those of the publisher, the editors and the reviewers. Any product that may be evaluated in this article, or claim that may be made by its manufacturer, is not guaranteed or endorsed by the publisher.

Copyright (C) 2021 Rivera, Infanti, Kumar and Mutemi. This is an open-access article distributed under the terms of the Creative Commons Attribution License (CC BY). The use, distribution or reproduction in other forums is permitted, provided the original author(s) and the copyright owner(s) are credited and that the original publication in this journal is cited, in accordance with accepted academic practice. No use, distribution or reproduction is permitted which does not comply with these terms. 